Check for updates

Cite this: J. Mater. Chem. A, 2020, 8 , 9392

Received 7th February 2020

Accepted 21st April 2020

DOI: 10.1039/d0ta01502d

rsc.li/materials-a

\section{Mechanisms of carbon dioxide reduction on strontium titanate perovskites}

\author{
Umberto Terranova, (D) *abc Francesc Viñes, (D) c Nora H. de Leeuw (iD) ad \\ and Francesc Illas (iD c
}

\begin{abstract}
Strontium titanate $\left(\mathrm{SrTiO}_{3}\right)$ is a promising material for the light-driven conversion of carbon dioxide $\left(\mathrm{CO}_{2}\right)$ into renewable fuels. However, the mechanisms of the relevant reactions are not yet well understood. In this work, we have used density functional theory calculations to explore $\mathrm{CO}_{2}$ reduction on the (001) surface of the $\mathrm{SrTiO}_{3}$ photocatalyst. Our results indicate that, in contrast to $\mathrm{COOH}$, the formation of a $\mathrm{HCOO}$ or $\mathrm{CO}_{2}{ }^{-}$intermediate is thermodynamically hindered, which is consistent with the fact that formic acid $(\mathrm{HCOOH})$ is not a major product in the experiments reported in the literature. We show that a pathway to carbon monoxide ( $\mathrm{CO}$ ) is instead possible, and that the formation of $\mathrm{COOH}$ is the ratelimiting step. Finally, we suggest that substitutional doping of $\mathrm{Sr}$ ions represents a promising approach to lower the energy barrier of the $\mathrm{COOH}$ formation.
\end{abstract}

\section{Introduction}

To reduce the still increasing $\mathrm{CO}_{2}$ emissions responsible for global warming and the concomitant climate change remains one of the biggest challenges of our era. The catalytic technologies currently being explored to utilise the $\mathrm{CO}_{2}$ molecule by converting it into useful hydrocarbons include heterogeneous $\mathbf{s}^{\mathbf{1 - 4}}$ and electrochemical ${ }^{5-7}$ catalysis. Approaches such as photocatalysis, ${ }^{\mathbf{8} 9}$ mimicking the natural process of photosynthesis, are particularly attractive, as they are achieved at room temperature and require only the harnessing of solar light as a source of energy. However, the achievement of photocatalytic conversions suitable to industrial applications remains a difficult challenge, ${ }^{10}$ which motivates the continuous search for new and improved photocatalytic materials.

Since their first use in heterogeneous catalysis in 1952, ${ }^{11}$ perovskite oxides have attracted significant interest in a diverse range of reactions, ${ }^{12}$ especially because they are cheaper and easier to prepare than metal-based catalysts such as platinum or palladium. ${ }^{13}$ Compared to other widely investigated oxide photocatalysts, e.g. $\mathrm{ZrO}_{2}$ and $\mathrm{Ga}_{2} \mathrm{O}_{3}$, perovskite oxides have bandgaps with a better overlap with the solar spectrum. In addition, owing to the unique flexibility of their structure, perovskite oxides have bands edges which can be tuned to

${ }^{a}$ School of Chemistry, Cardiff University, Cardiff, CF10 3AT, UK. E-mail: umberto. terranova@buckingham.ac.uk

${ }^{b}$ School of Postgraduate Medicine and Allied Health, Crewe Campus, University of Buckingham, Crewe, CW1 5DU, UK

${ }^{c}$ Departament de Ciència de Materials i Química Física, Institut de Quìmica Teòrica $i$ Computacional (IQTCUB), Universitat de Barcelona, c/Martí i Franquès 1-11, 08028, Barcelona, Spain

${ }^{d}$ Department of Earth Sciences, Utrecht University, 3584 CD Utrecht, The Netherlands facilitate both the reduction of $\mathrm{CO}_{2}$ and the oxidation of water during the photocatalytic process. ${ }^{9}$

Because of their striking photochemical stabilities, titanate perovskites are particularly promising for $\mathrm{CO}_{2}$ photocatalysis. ${ }^{\mathbf{1 4}}$ Taking inspiration from leaves, Zhou et al. have developed an artificial photosynthetic system based on titanate perovskites which generates carbon monoxide and methane from $\mathrm{CO}_{2}$ and water. ${ }^{\mathbf{1 5}}$ These materials have also been investigated in combination with other semiconductors, co-catalysts and dopants, in the effort to improve their conversion efficiencies. For example, Li et al. obtained $\mathrm{CO}$ and $\mathrm{H}_{2}$ by loading $\mathrm{SrTiO}_{3}$ with noble metals ${ }^{16}$ while $\mathrm{CaTiO}_{3}$ samples loaded with $\mathrm{Ag}$ exhibited stable photocatalytic activities for $\mathrm{CO}_{2}$ reduction to $\mathrm{CO}$ using water as an electron donor. ${ }^{17}$ The photoreduction of $\mathrm{CO}_{2}$ on $\mathrm{SrTiO}_{3}$ based nanocomposite systems has also been demonstrated, with $\mathrm{CH}_{4}$ as the major product. ${ }^{18}$ The generation of oxygen vacancies enhances the adsorption of $\mathrm{CO}_{2}$ on $\mathrm{SrTiO}_{3}$, leading to higher yields of $\mathrm{CH}_{4},{ }^{19}$ while $\mathrm{NaTaO}_{3}$ doped with $\mathrm{Ba}$, $\mathrm{Ca}$, and $\mathrm{Sr}$ has shown high activity towards $\mathrm{CO}_{2}$ reduction to $\mathrm{CO}$ in water. ${ }^{20}$

Detailed atomistic knowledge of the light-triggered catalytic reaction mechanism is crucial to help design better photocatalysts. ${ }^{21}$ For example, it allows us to ascertain the limiting reaction steps, featuring the higher activation energy barriers in a catalytic pathway, which elucidates ways of fine-tuning the perovskite structure to lower these activation barriers. However, in contrast to the most investigated anatase $\mathrm{TiO}_{2}$ photocatalysts, ${ }^{22}$ the elementary reaction steps occurring after the adsorption of $\mathrm{CO}_{2}$ on titanate perovskites are yet to be clarified.

Here, we provide this missing piece of information on the textbook $\mathrm{SrTiO}_{3}$ perovskite, one of the most commonly investigated members of the titanate perovskite family, which, with a tunable bandgap of $3.2 \mathrm{eV}$ (ref. 23) (identical to that of 
anatase) and remarkable charge transport properties, ${ }^{\mathbf{1 4}}$ holds great potential as a photocatalyst. ${ }^{1924-27}$ Using simulations within the density functional theory (DFT), we first aim to achieve the description of a realistic reaction pathway for the experimentally observed reduction of $\mathrm{CO}_{2}$ to $\mathrm{CO}$. Afterwards, we take advantage of the fresh insights into the system to put forward a doping approach aimed at improving the efficiency of the photocatalytic reaction.

\section{Models and methods}

The most-stable $\mathrm{SrTiO}_{3}$ (001) surface can have two different competitive terminations, namely $\mathrm{SrO}$ and $\mathrm{TiO}_{2} \cdot{ }^{28}$ In this study, we have focussed on the SrO termination only, since its equivalent has been shown generally to be the favoured plane in a wide diversity of perovskites. ${ }^{29,30}$ Our (001) surface model, built from an optimised primitive cell, consists of a $2 \times 2 \times 4$ supercell, and contains 80 atoms located within 8 layers. Surface slabs were separated by a vacuum region of $15 \AA$ along the normal direction to avoid spurious interactions between periodic images. All structures were drawn with the visualization for electronic and structural analysis (VESTA) program suite. $^{31}$

The adsorption energy of $\mathrm{CO}_{2}$ was evaluated according to the formula

$$
E_{\mathrm{ads}}=E_{\mathrm{slab} / \mathrm{mol}}-E_{\mathrm{slab}}-E_{\mathrm{mol}}
$$

where $E_{\mathrm{slab} / \mathrm{mol}}$ is the energy of the supercell with the adsorbed $\mathrm{CO}_{2}$, while $E_{\text {slab }}$ and $E_{\text {mol }}$ are the energy of the same supercell with, respectively, only the surface slab or a $\mathrm{CO}_{2}$ molecule. In addition to the DFT energy $E$, in order to take into account the effect of temperature and pressure in the reaction mechanism, we have considered the Gibbs free energy $G$. For a condensed phase structure, $G$ is defined as

$$
G=E+F_{\mathrm{vib}}+p V
$$

where $F_{\text {vib }}$ is the vibrational contribution to the free energy, which we have estimated using the frequencies at the $\Gamma$-point. The $p V$ term can be neglected, as it is of the order of meV under standard working conditions. ${ }^{32}$ The Gibbs free energy of a gasphase molecule corresponds to its chemical potential $\mu$, which can be derived from ${ }^{33}$

$\mu(T, p)=\mu_{\mathrm{ref}}\left(T_{0}, p_{0}\right)+\Delta H\left(T, p_{0}\right)-T \Delta S\left(T, p_{0}\right)+k_{\mathrm{B}} T \log \left(p / p_{0}\right),(3)$

where $\Delta H$ and $\Delta S$ are the enthalpy and entropy variations from the reference chemical potential $\mu_{\text {ref }}$ and $k_{\mathrm{B}} T \log \left(p / p_{0}\right)$ includes the effect of pressure on the chemical potential with respect to the standard one. If $T_{0}=0 \mathrm{~K}, \mu_{\text {ref }}$ can be approximated by the DFT energy of the molecule in the gas-phase, including the zero point energy contribution. Thus, eqn (3) allows us to calculate the chemical potential of $\mathrm{CO}_{2}, \mathrm{CO}, \mathrm{H}_{2} \mathrm{O}$ and $\mathrm{H}_{2}$ at given temperature and pressure by using their respective tabulated enthalpy and entropy values at the standard ambient pressure $p_{0}{ }^{34}$
The substitutional energy for the dopant $\mathrm{X}(\mathrm{X}=\mathrm{Ba}$ or $\mathrm{Ca})$ was calculated according to

$$
E_{\text {subs }}(\mathrm{X})=E(\text { doped })+E(\mathrm{Sr})-E(\text { undoped })-E(\mathrm{X}),
$$

where $E$ (doped) and $E$ (undoped) are the energies of doped and pure $\mathrm{SrTiO}_{3}$ surfaces, respectively, while $E(\mathrm{Sr})$ and $E(\mathrm{X})$ are the energies of single $\mathrm{Sr}$ and $\mathrm{X}$ atoms.

All DFT calculations were performed with the VASP 5.3 package $^{35,36}$ using the Perdew-Burke-Ernzerhof (PBE) functional. ${ }^{37}$ We have employed the projector augmented wave method to model the core-electron interaction, ${ }^{38}$ treating explicitly the following electrons: $\mathrm{Sr} 4 \mathrm{~s} 4 \mathrm{p} \mathrm{5s}$; Ti 3d 4s; O 2s 2p; Ba 5s 5p 6s; Ca 3s 3p 4s. All calculations were performed with a plane wave cutoff of $500 \mathrm{eV}$, which guarantees that the absolute energies of bulk $\mathrm{SrTiO}_{3}$ are converged within 2 meV per atom. Calculations were stopped when the forces acting on the ions were less than $10^{-2} \mathrm{eV} \AA^{-1}$. After finding that a $6 \times 6 \times 6$ Monkhorst-Pack grid ${ }^{39}$ ensures that the absolute energies of bulk $\mathrm{SrTiO}_{3}$ are converged to better than $1 \mathrm{meV}$ per atom, we scaled the grids of the surface calculations inversely with the dimension of the unit cells to $3 \times 3 \times 1$. We have also undertaken test calculations to make sure that the atomic relaxations in the surface slab are converged with respect to its thickness. Transition states were located with the climbing image nudged elastic band algorithm. ${ }^{40}$ The number of images used varied from one to four, depending on the elementary reaction step. We have calculated vibrational frequencies under the harmonic approximation and with Hessian matrix elements estimated from finite differences of analytical gradients with displacements of $0.015 \AA$ in length. Only the degrees of freedom of the adsorbate species and the atoms in the topmost atomic layer of the surface have been included in the vibrational analysis.

\section{Results and discussion}

\subsection{Adsorption of $\mathrm{CO}_{2}$}

A sufficiently large number of different adsorption configurations for $\mathrm{CO}_{2}$ on the SrO-terminated $\mathrm{SrTiO}_{3}$ (001) surface have been probed to ensure that realistic minimum energy structures would be obtained. Following optimisation, all configurations relaxed towards the structure depicted in Fig. 1, where the arrangement of the atoms at the adsorption site resembles that of a $\mathrm{CO}_{3}{ }^{2-}$ carbonate ion. In particular, each carbonyl oxygen forms a bridging bond with two surface $\mathrm{Sr}$ ions, whereas the remaining oxygen, $\mathrm{O}_{\mathrm{s}}$, is significantly displaced from its surface position. The $\mathrm{C}-\mathrm{O}$ and $\mathrm{C}-\mathrm{O}_{\mathrm{s}}$ bond lengths are 1.27 and $1.36 \AA$, respectively, while the $\mathrm{O}_{1}-\mathrm{C}-\mathrm{O}_{2}$ angle of $122.4^{\circ}$ confirms the strong interaction with the surface, as shown by the large adsorption energy of $-1.82 \mathrm{eV}$. All of these values are in line with a $\mathrm{CO}_{2}$ capture and activation process. ${ }^{41}$ Both the geometry and the energetics, which are summarised in Table 1, are comparable to those found in a previous DFT investigation by Sopiha et al. ${ }^{42}$ who also showed that the adsorption geometry of $\mathrm{CO}_{2}$ slightly changes, while its interaction becomes stronger, when the size of the surface unit cell is increased from a $2 \times 2$ to a $3 \times 3$ supercell. As the structure in Fig. 1 is the only stable on 

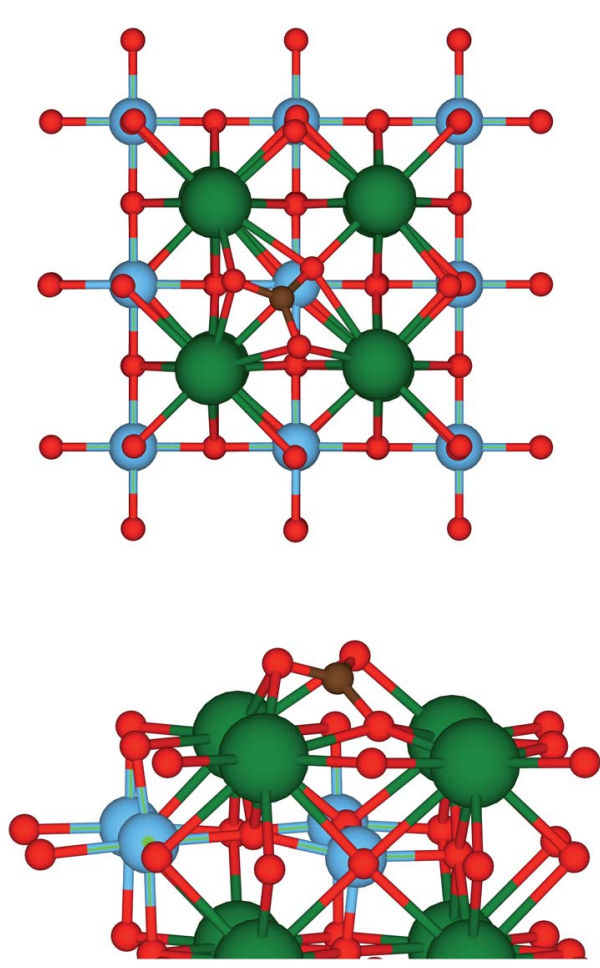

Fig. 1 Top (upper panel) and side (lower panel) views of the adsorption structure of $\mathrm{CO}_{2}$ on the $\mathrm{SrO}$-terminated (001) surface of $\mathrm{SrTiO}_{3}$. Colour code: $\mathrm{Sr}$ - green, $\mathrm{Ti}$ - blue, $\mathrm{O}$ - red, $\mathrm{C}$ - brown.

Table 1 Adsorption energy and main geometrical parameters of the adsorption structure of $\mathrm{CO}_{2}$ on the $\mathrm{SrO}$-terminated (001) surface of $\mathrm{SrTiO}_{3}$ depicted in Fig. 1

\begin{tabular}{lllll}
\hline$E_{\text {ads }}(\mathrm{eV})$ & $\mathrm{C}-\mathrm{O}_{1}(\AA)$ & $\mathrm{C}-\mathrm{O}_{2}(\AA)$ & $\mathrm{C}-\mathrm{O}_{\mathrm{s}}(\AA)$ & $\mathrm{O}_{1}-\mathrm{C}-\mathrm{O}_{2}\left({ }^{\circ}\right)$ \\
\hline-1.82 & 1.27 & 1.27 & 1.36 & 122.4
\end{tabular}

the $2 \times 2$ unit cell which we adopted, we assume that any reaction pathway must include it as a reactant configuration. However, we stress that other starting configurations, potentially leading to different reduction mechanisms, may also be possible at lower $\mathrm{CO}_{2}$ coverages.

It is instructive, at this point, to compare the adsorption energy of this structure with that of a water molecule. Regardless of the initial configuration and in line with the literature, ${ }^{43}$ we found that water spontaneously dissociates on the SrOterminated (001) surface of $\mathrm{SrTiO}_{3}$. The dissociated water molecule is adsorbed with an energy of $-1.26 \mathrm{eV}$, which is considerably less negative than the $-1.82 \mathrm{eV}$ value found for $\mathrm{CO}_{2}$. As a result, we expect $\mathrm{SrTiO}_{3}$ to be preferentially covered by $\mathrm{CO}_{2}$ rather than by water, which in turn suggests that the $\mathrm{CO}_{2}$ reduction process should be more favourable than the competing hydrogen evolution reaction. ${ }^{\mathbf{1 0}}$ Future detailed studies can now build on these findings to confirm the selectivity of $\mathrm{SrTiO}_{3}$ towards the reduction of $\mathrm{CO}_{2}$, rather than water.

\subsection{Thermodynamics of intermediates}

The photocatalytic conversion of $\mathrm{CO}_{2}$ takes place in the presence of a photoexcited electron which reduces the $\mathrm{SrTiO}_{3}$ surface. When the carbonate-like structure described above is adsorbed on the reduced surface, which we have modelled by adsorbing a $\mathrm{H}$ atom on $\mathrm{SrTiO}_{3}$ as in previous works, ${ }^{22,44}$ a hydrogen bond between a carbonyl oxygen and the proton on the surface is formed, which is illustrated in Fig. 2a. However, the geometry changes with respect to the neutral surface, e.g. the elongation of the two $\mathrm{C}-\mathrm{O}$ bonds, are only marginal, as can be seen from the parameters reported in Table 2 .

$\mathrm{TiO}_{2}$ is arguably the prototype photocatalyst, ${ }^{45}$ and many efforts have been devoted to the elucidation of the molecular mechanisms yielding fuels from $\mathrm{CO}_{2}$ using $\mathrm{TiO}_{2}$ polymorphs. He et al. concluded that the formation of an activated $\mathrm{CO}_{2}{ }^{-}$ radical adsorbed in a bridging configuration is the first step towards hydrogenation and the formation of formic acid on anatase. ${ }^{22}$ In search of a possible similar mechanism, we have relaxed such a structure. While not stable on a neutral surface, interestingly, in the presence of a reducing electron, this bent geometry converged to one with a $\mathrm{O}_{1}-\mathrm{C}-\mathrm{O}_{2}$ angle of $140.4^{\circ}$, see Fig. $2 \mathrm{~b}$ and Table 2, which highlights the importance of photogenerated electrons on the activation of the molecule. However, its energy resulted to be $1.96 \mathrm{eV}$ higher than that of the carbonate-like structure in Fig. 2a, which makes it an unlikely candidate as a possible intermediate, while indicating that catalytic mechanisms different than those of $\mathrm{TiO}_{2}$ are at play in $\mathrm{SrTiO}_{3}$.
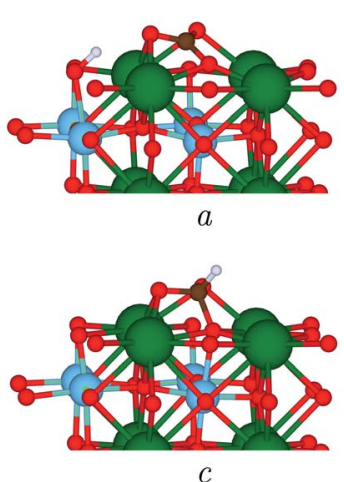

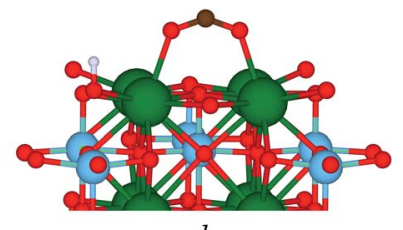

b

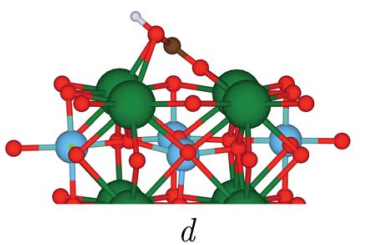

Fig. 2 Side views of the structures discussed in the text. $\mathrm{CO}_{2}$ adsorption on a reduced surface (a); activated $\mathrm{CO}_{2}$ in a bridging bidentate configuration similar to that observed in anatase $\mathrm{TiO}_{2}$ (b); $\mathrm{HCOO}$ structure with hydrogenation at the $\mathrm{C}$ atom (c); $\mathrm{COOH}$ structure with formation of a $\mathrm{O}-\mathrm{H}$ bond (d); Colour code: $\mathrm{Sr}$ - green, $\mathrm{Ti}-$ blue, $\mathrm{O}$ - red, $\mathrm{C}$ - brown, $\mathrm{H}$ - white.

Table 2 Relative energies and main geometrical parameters of the different $\mathrm{CO}_{2}$ adsorptions on the $\mathrm{SrO}$-terminated (001) surface of $\mathrm{SrTiO}_{3}$. Labels refer to Fig. 2

\begin{tabular}{llllll}
\hline Label & $E(\mathrm{eV})$ & $\mathrm{C}-\mathrm{O}_{1}(\AA)$ & $\mathrm{C}-\mathrm{O}_{2}(\AA)$ & $\mathrm{C}-\mathrm{O}_{\mathrm{s}}(\AA)$ & $\mathrm{O}_{1}-\mathrm{C}-\mathrm{O}_{2}\left({ }^{\circ}\right)$ \\
\hline (a) & 0.00 & 1.29 & 1.30 & 1.32 & 121.6 \\
(b) & 1.96 & 1.23 & 1.23 & - & 140.4 \\
(c) & 2.55 & 1.38 & 1.38 & 1.45 & 110.6 \\
(d) & 1.15 & 1.41 & 1.25 & 1.27 & 117.3
\end{tabular}


Next, we assessed whether hydrogenation of $\mathrm{CO}_{2}$ could occur via a different intermediate. Thus, we detached the adsorbed $\mathrm{H}$ species from the surface site of Fig. 2a, creating a new $\mathrm{H}-\mathrm{C}$ bond, see Fig. 2c. However, we found the energy of the resulting configuration to be $2.55 \mathrm{eV}$ higher than that of the original structure, which clearly excludes its participation in any reaction mechanism.

Finally, we relaxed the structure in Fig. 2d, where we simulated the $\mathrm{H}$ transfer from the surface site of structure of Fig. 2a to the closest $\mathrm{CO}_{2}$ oxygen. The formation of a $\mathrm{COOH}$ group changes the adsorption geometry to that of a bridging bidentate, having an energy $1.15 \mathrm{eV}$ higher than the initial structure, taken as reference, as shown in Table 2.

On the basis of thermodynamic (energetic) considerations, we can conclude that only the $\mathrm{COOH}$ intermediate can participate in the reduction of $\mathrm{CO}_{2}$, while pathways involving either $\mathrm{CO}_{2}{ }^{-}$and/or HCOO should be discarded. However, we cannot rule out the existence of other, in principle less favoured, pathways where two or more electrons and/or proton are transferred. $^{22}$ The high energy penalty for hydrogenation through the carbon atom explains why $\mathrm{HCOOH}$ is not detected in $\mathrm{CO}_{2}$ photochemical reactions on $\mathrm{SrTiO}_{3}$. Instead, the $\mathrm{COOH}$ species that can be reached energetically points to a pathway towards $\mathrm{CO},{ }^{10}$ in agreement with experimental findings on titanate perovskites. ${ }^{15,16}$

\subsection{Reaction pathway to $\mathrm{CO}$}

With the information gained in the previous section, we have derived a realistic pathway for the reduction of $\mathrm{CO}_{2}$ to $\mathrm{CO}$, which we present in the top panel of Fig. 3, whereas reaction geometries are shown in Fig. 4. The formation of the $\mathrm{COOH}$ intermediate proceeds via TS1 and has an activation energy barrier for the hydrogen transfer of $1.22 \mathrm{eV}$. Only $0.75 \mathrm{eV}$ is required to reach TS2 (where the $\mathrm{C}-\mathrm{O}$ distance is $1.56 \AA$ ), break the $\mathrm{C}-\mathrm{O}$ bond and form the $\mathrm{CO}$ and $\mathrm{OH}$ species at the surface. Note, however, that the barrier for $\mathrm{CO}$ and $\mathrm{OH}$ recombination is lower, which may indicate that, from a kinetic point of view, a substantial part of reactions will go backwards, with forward direction favoured by fast $\mathrm{CO}$ and $\mathrm{OH}$ diffusions. The subsequent release of $\mathrm{CO}$ is endothermic by merely $0.12 \mathrm{eV}$, and the process leaves a hydrogen-bonded $\mathrm{H}^{+}$and $\mathrm{OH}^{-}$couple. In the last step of the reaction mechanism, as a result of a proton transfer in TS3, a $\mathrm{H}_{2} \mathrm{O}$ molecule forms. This water molecule interacts with the surface by means of two hydrogen bonds, and its desorption raises the energy by $0.86 \mathrm{eV}$. The entire reaction cycle, $\mathrm{CO}_{2}+2 \mathrm{H}^{+}+2 \mathrm{e}^{-} \rightarrow \mathrm{CO}+\mathrm{H}_{2} \mathrm{O}$, is endothermic by $0.73 \mathrm{eV}$. Obviously, the energy profile provides a preliminary picture of the overall mechanism, allowing to discard the HCOO intermediate. However, to unravel the amount of $\mathrm{CO}$ formed and the effect of $\mathrm{H}_{2} \mathrm{O}$ requires further analysis that is beyond the scope of the present work. Note also, that the models used represent the ideal (001) surface, whereas the real material may be more complex. In any case, the present results provide some clear and unbiased hints that explain experimental observations.

In the bottom panel of Fig. 3, we plot the Gibbs free energy of the pathway above, taking into account temperature $(300 \mathrm{~K})$ and
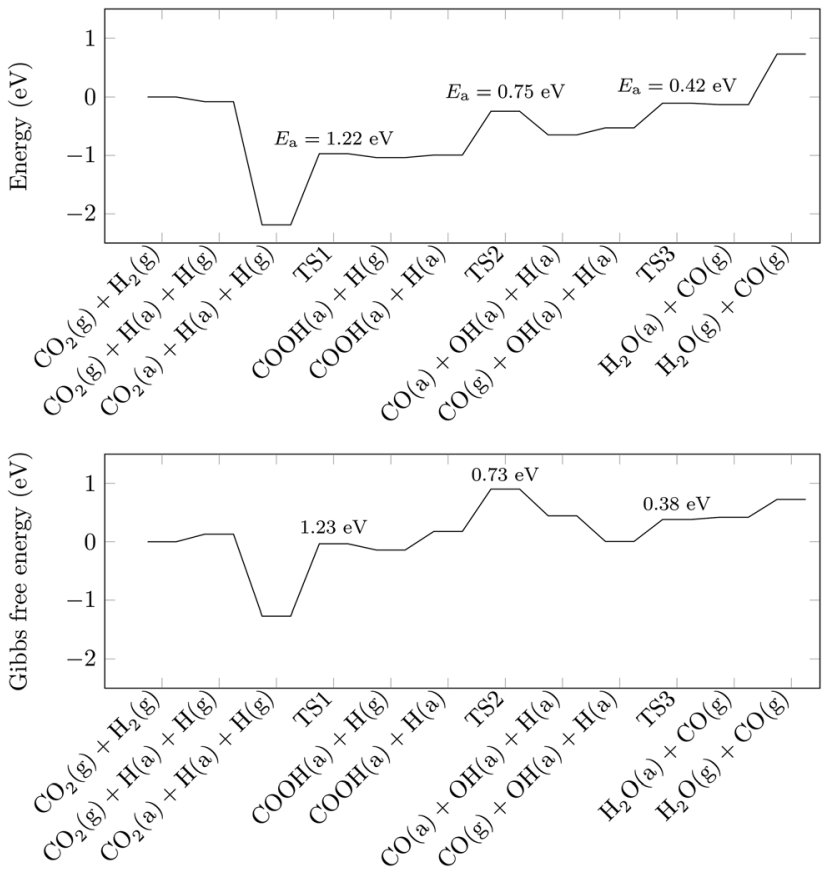

Fig. 3 Reaction pathways for the reduction of $\mathrm{CO}_{2}$ to $\mathrm{CO}$ on $\mathrm{SrTiO}_{3}$. Structures are labelled according to the state of the species. (a) indicates that the species is adsorbed on the surface, while $(\mathrm{g})$ indicates that the species is modelled in the gas-phase and does not interact with the surface. Transition states are indicated as TS1, TS2 and TS3. The zero of the energies are taken as those of structure $\mathrm{CO}_{2}(\mathrm{~g})+\mathrm{H}_{2}(\mathrm{~g})$. Activation energies $\left(E_{\mathrm{a}}\right)$ are shown.

pressure ( 1 bar) effects. The profile flattens compared to that in the top panel of Fig. 3, although the endothermicity of the reaction is not much affected. The flattening can be explained by the larger entropy contributions carried by the gaseous species compared to their adsorbed counterparts. For example, the gain due to the adsorption of $\mathrm{CO}_{2}$ increases drastically, from -2.11 to $-1.40 \mathrm{eV}$, when the Gibbs free energy, rather than the DFT energy, is considered. However, the rate limiting step remains the formation of the $\mathrm{COOH}$ group, whose activation energy barrier remains virtually unchanged at $1.23 \mathrm{eV}$, which is in line with the low photoreduction rates typical of titanate perovskites. ${ }^{46}$ Note, however, that once pressure and temperature effects are taken into account, the thermodynamics will tend to drive the reaction backwards since now some transition states are located above the desorption limit. This is an issue deserving further attention through macroscopic simulations including all elementary steps and searching for the optimum operating conditions as well.

\subsection{Substitutional doping}

Having established that the formation of the $\mathrm{COOH}$ intermediate (more favoured than its desorption from the surface by around $0.1 \mathrm{eV}$, as shown in Fig. 3), is the rate-limiting step in the production of $\mathrm{CO}$ on the pure $\mathrm{SrTiO}_{3}$ (001) surface, we have carried out further calculations to explore how the activation energy of this elementary reaction step is affected by surface doping. Similar to the study by Carlotto et al., ${ }^{47}$ we have only 


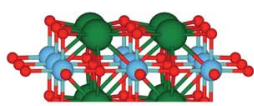

$\mathrm{CO}_{2}(\mathrm{~g})+\mathrm{H}_{2}(\mathrm{~g})$
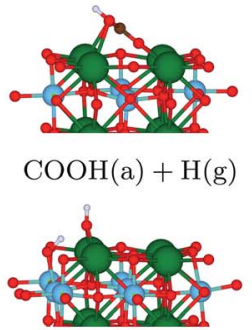

$\mathrm{CO}(\mathrm{g})+\mathrm{OH}(\mathrm{a})+\mathrm{H}(\mathrm{a})$

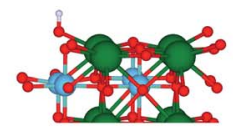

$\mathrm{CO}_{2}(\mathrm{~g})+\mathrm{H}(\mathrm{a})+\mathrm{H}(\mathrm{g})$

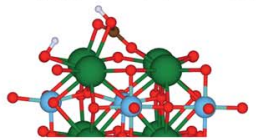

$\mathrm{COOH}(\mathrm{a})+\mathrm{H}(\mathrm{a})$

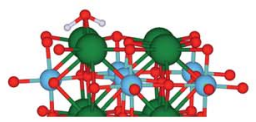

TS3

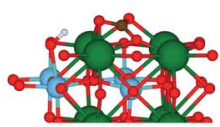

$\mathrm{CO}_{2}(\mathrm{a})+\mathrm{H}(\mathrm{a})+\mathrm{H}(\mathrm{g})$

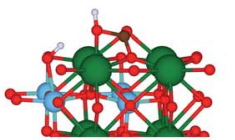

TS2

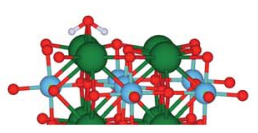

$\mathrm{H}_{2} \mathrm{O}(\mathrm{a})+\mathrm{CO}(\mathrm{g})$

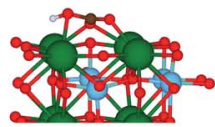

TS1

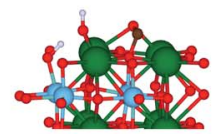

$\mathrm{CO}(\mathrm{a})+\mathrm{OH}(\mathrm{a})+\mathrm{H}(\mathrm{a})$

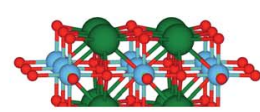

$\mathrm{H}_{2} \mathrm{O}(\mathrm{g})+\mathrm{CO}(\mathrm{g})$

Fig. 4 Side views of the structures participating in the reaction pathway illustrated in Fig. 3. Colour code: $\mathrm{Sr}-\mathrm{green}, \mathrm{Ti}-\mathrm{blue}, \mathrm{O}-\mathrm{red}, \mathrm{C}-$ brown, $\mathrm{H}$ - white.

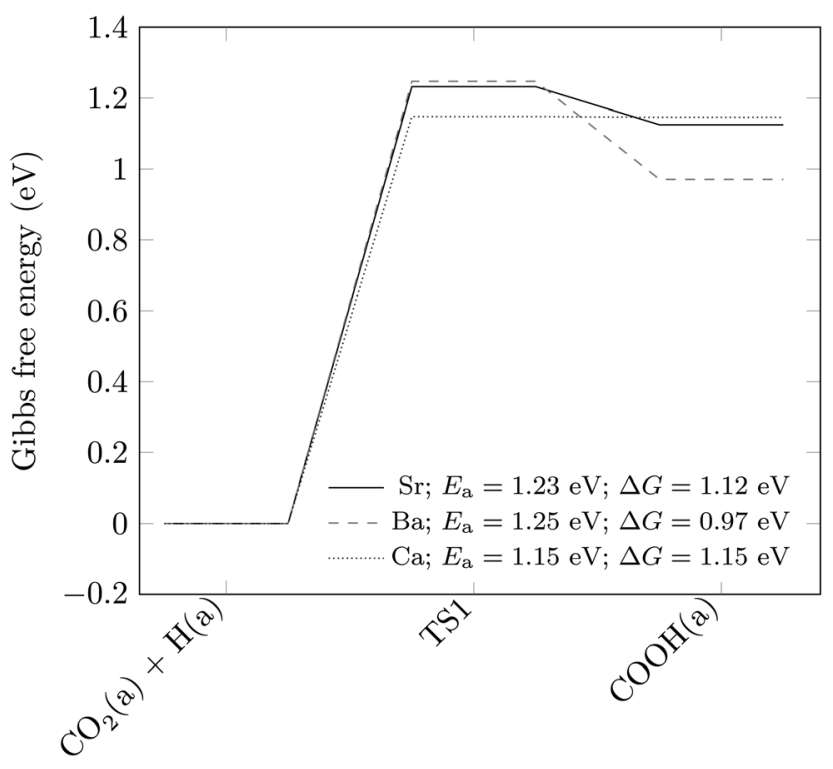

Fig. 5 Energetics of the rate-limiting $\mathrm{COOH}$ formation step of Fig. 3, with and without substitutional doping of $\mathrm{Sr}$ ions. Structures are labelled according to the state of the species. (a) indicates that the species is adsorbed on the surface. The transition state is indicated as TS1. The zero of the Gibbs free energy is taken as that of structure $\mathrm{CO}_{2}(\mathrm{a})+\mathrm{H}(\mathrm{a})$. Activation energies $\left(E_{\mathrm{a}}\right)$ and differences in Gibbs free energies $(\Delta G)$ are also included.

focussed on the top surface layer. In particular, we have considered the substitution of one of the four Sr ions by a Ba or $\mathrm{Ca}$ ion. We have chosen these dopants because their ionic radii in the 2+ charge state, at 149 and 114 pm, respectively, are close to the $132 \mathrm{pm}$ ionic radius of $\mathrm{Sr},{ }^{\mathbf{4 8}}$ which implies that they should be accommodated easily within the $\mathrm{SrTiO}_{3}$ material, both geometrically and in terms of charge. Moreover, $\mathrm{BaTiO}_{3}$ and $\mathrm{CaTiO}_{3}$ are the most common titanate perovskites after $\mathrm{SrTiO}_{3}$, which should ensure the successful replacement of $\mathrm{Sr}$ by $\mathrm{Ba}$ and $\mathrm{Ca}$ ions during the synthesis of the photocatalyst. The stability of the doped materials is suggested by the negative substitutional energies of both dopants, i.e. -0.26 and $-0.09 \mathrm{eV}$, respectively, for $\mathrm{Ba}$ and $\mathrm{Ca}$.

Fig. 5 shows the activation energy barriers of the elementary steps and the difference in Gibbs free energy between the two intermediates. While Ba dopants change the thermodynamics of the reaction step without altering its kinetics, the substitution of Sr by Ca ions has the opposite effect, with the activation barrier being lowered from 1.23 to $1.15 \mathrm{eV}$. Although the effect is small, it clearly indicates that cation doping is a conceivable way to accelerate the reaction rate for CO production over the $\mathrm{SrTiO}_{3}$ photocatalyst, as shown here by Ca.

\section{Conclusions}

We have presented a theoretical investigation of the adsorption and reaction of $\mathrm{CO}_{2}$ on the SrO-terminated (001) surface of $\mathrm{SrTiO}_{3}$, a perovskite compound of significant technological interest. We have shown that the possible intermediates towards the formation of $\mathrm{HCOOH}$ are very high in energy, which explains why the formation of $\mathrm{HCOOH}$ is not normally reported in photocatalytic experiments. Instead, the reduction of $\mathrm{CO}_{2}$ to $\mathrm{CO}$ appears to be feasible, in agreement with experimental observations, thus pointing towards to the use of $\mathrm{SrTiO}_{3}$ as a photocatalyst for the reduction of $\mathrm{CO}_{2}$. The reaction occurs via the formation of a $\mathrm{COOH}$ species (the associative mechanism in the reverse water gas shift reaction ${ }^{3}$ ), with an activation energy of about $1.2 \mathrm{eV}$, corresponding to the rate-limiting step of the overall reaction.

However, a more firm statement will require a systematic analysis of adsorption/desorption rates, the rates for diffusion of the various species and their comparison to reaction rates for all the steps in the mechanism. While such simulations are left for subsequent work, the present results provide compelling evidence that the barrier for the likely rate determining step is sensitive to the nature of the surface cations, and therefore can be lowered by means of a doping strategy, for example where smaller $\mathrm{Ca}$ ions substitute for $\mathrm{Sr}$ ions. Future experimental studies along with macroscopic simulations will be important to validate these predictions. 


\section{Conflicts of interest}

There are no conflicts to declare.

\section{Acknowledgements}

This work has been performed under the HPC-EUROPA3 (INFRAIA-2016-1-730897) project, with the support of the EC Research Innovation Action under the H2020 Programme. UT gratefully acknowledges the support of the computer resources and the technical support provided by the Barcelona Supercomputing Center-Centro Nacional de Supercomputación. This work was supported by the Engineering and Physical Sciences Research Council (grant EP/K009567/2), and used the ARCHER UK National Supercomputing Service (http://www.archer.ac.uk) via our membership of the UK's HEC Materials Chemistry Consortium, which is funded by EPSRC (EP/L000202). FV and FI acknowledge financial support from the Ministerio de Ciencia, Innovación y Universidades MICIUN RTI2018-095460-B-I00, and María de Maeztu MDM-2017-0767 grants and, in part, Generalitat de Catalunya 2017SGR13 and XRQTC grants. FV is thankful to the Ministerio de Economía y Competitividad (MEC) for his Ramón y Cajal (RYC-2012-10129) research contract, and FI acknowledges additional support from the 2015 ICREA Academia Award for Excellence in University Research. All data created during this research are openly available from the Cardiff University Research Portal at http://doi.org/10.17035/ d.2019.0086887209.

\section{References}

1 J. Ma, N. Sun, X. Zhang, N. Zhao, F. Xiao, W. Wei and Y. Sun, A short review of catalysis for $\mathrm{CO}_{2}$ conversion, Catal. Today, 2009, 148, 221-231.

2 M. K. Gnanamani, G. Jacobs, H. H. Hamdeh, W. D. Shafer, F. Liu, S. D. Hopps, G. A. Thomas and B. H. Davis, Hydrogenation of carbon dioxide over Co-Fe bimetallic catalysts, ACS Catal., 2016, 6, 913-927.

3 X. Liu, C. Kunkel, P. Ramírez de la Piscina, N. Homs, F. Viñes and F. Illas, Effective and Highly Selective CO Generation from $\mathrm{CO}_{2}$ Using a Polycrystalline- $\mathrm{Mo}_{2} \mathrm{C}$ Catalyst, ACS Catal., 2017, 7, 4323-4335.

4 C. E. Mitchell, U. Terranova, I. Alshibane, D. J. Morgan, T. E. Davies, Q. He, J. S. Hargreaves, M. Sankar and N. H. de Leeuw, Liquid phase hydrogenation of $\mathrm{CO}_{2}$ to formate using palladium and ruthenium nanoparticles supported on molybdenum carbide, New J. Chem., 2019, 43, 13985-13997.

5 D. T. Whipple and P. J. Kenis, Prospects of $\mathrm{CO}_{2}$ utilization via direct heterogeneous electrochemical reduction, J. Phys. Chem. Lett., 2010, 1, 3451-3458.

6 B. Kumar, J. P. Brian, V. Atla, S. Kumari, K. A. Bertram, R. T. White and J. M. Spurgeon, New trends in the development of heterogeneous catalysts for electrochemical $\mathrm{CO}_{2}$ reduction, Catal. Today, 2016, 270, 19-30.
7 A. Roldán, N. Hollingsworth, A. Roffey, H.-U. Islam, J. B. M. Goodall, C. R. A. Catlow, J. A. Darr, W. Bras, G. Sankar, K. B. Holt, et al., Bio-inspired $\mathrm{CO}_{2}$ conversion by iron sulfide catalysts under sustainable conditions, Chem. Commun., 2015, 51, 7501-7504.

8 D. Ravelli, D. Dondi, M. Fagnoni and A. Albini, Photocatalysis. A multifaceted concept for green chemistry, Chem. Soc. Rev., 2009, 38, 1999-2011.

9 S. Zeng, P. Kar, U. K. Thakur and K. Shankar, A review on photocatalytic $\mathrm{CO}_{2}$ reduction using perovskite oxide nanomaterials, Nanotechnology, 2018, 29, 052001.

10 X. Chang, T. Wang and J. Gong, $\mathrm{CO}_{2}$ photo-reduction: insights into $\mathrm{CO}_{2}$ activation and reaction on surfaces of photocatalysts, Energy Environ. Sci., 2016, 9, 2177-2196.

11 G. Parravano, Ferroelectric transitions and heterogenous catalysis, J. Chem. Phys., 1952, 20, 342-343.

12 J. Zhu, H. Li, L. Zhong, P. Xiao, X. Xu, X. Yang, Z. Zhao and J. Li, Perovskite oxides: preparation, characterizations, and applications in heterogeneous catalysis, ACS Catal., 2014, 4, 2917-2940.

13 S. Royer, D. Duprez, F. Can, X. Courtois, C. Batiot-Dupeyrat, S. Laassiri and H. Alamdari, Perovskites as Substitutes of Noble Metals for Heterogeneous Catalysis: Dream or Reality, Chem. Rev., 2014, 114, 10292-10368.

14 R. Shi, G. I. Waterhouse and T. Zhang, Recent progress in photocatalytic $\mathrm{CO}_{2}$ reduction over perovskite oxides, Sol. $R R L, 2017,1,1700126$.

15 H. Zhou, J. Guo, P. Li, T. Fan, D. Zhang and J. Ye, Leafarchitectured 3D hierarchical artificial photosynthetic system of perovskite titanates towards $\mathrm{CO}_{2}$ photoreduction into hydrocarbon fuels, Sci. Rep., 2013, 3, 1667.

16 D. Li, S. Ouyang, H. Xu, D. Lu, M. Zhao, X. Zhang and J. Ye, Synergistic effect of $\mathrm{Au}$ and $\mathrm{Rh}$ on $\mathrm{SrTiO}_{3}$ in significantly promoting visible-lightdriven syngas production from $\mathrm{CO}_{2}$ and $\mathrm{H}_{2} \mathrm{O}$, Chem. Commun., 2016, 52, 5989-5992.

17 H. Yoshida, L. Zhang, M. Sato, T. Morikawa, T. Kajino, T. Sekito, S. Matsumoto and H. Hirata, Calcium titanate photocatalyst prepared by a flux method for reduction of carbon dioxide with water, Catal. Today, 2015, 251, 132-139.

18 M. F. Ehsan, M. N. Ashiq, F. Bi, Y. Bi, S. Palanisamy and T. He, Preparation and characterization of $\mathrm{SrTiO}_{3}-\mathrm{ZnTe}$ nanocomposites for the visible light photoconversion of carbon dioxide to methane, $R S C A d v$. , 2014, 4, 48411-48418.

19 K. Xie, N. Umezawa, N. Zhang, P. Reunchan, Y. Zhang and J. Ye, Selfdoped $\mathrm{SrTiO}_{3-\delta}$ photocatalyst with enhanced activity for artificial photosynthesis under visible light, Energy Environ. Sci., 2011, 4, 4211-4219.

20 H. Nakanishi, K. Iizuka, T. Takayama, A. Iwase and A. Kudo, Highly active $\mathrm{NaTaO}_{3}$-based photocatalysts for $\mathrm{CO}_{2}$ reduction to form $\mathrm{CO}$ using water as the electron donor, ChemSusChem, 2017, 10, 112-118.

21 Y. Ji and Y. Luo, Theoretical Study on the Mechanism of Photoreduction of $\mathrm{CO}_{2}$ to $\mathrm{CH}_{4}$ on the Anatase $\mathrm{TiO}_{2}$ (101) Surface, ACS Catal., 2016, 6, 2018-2025.

22 H. He, P. Zapol and L. A. Curtiss, Computational screening of dopants for photocatalytic two-electron reduction of $\mathrm{CO}_{2}$ 
on anatase (101) surfaces, Energy Environ. Sci., 2012, 5, 61966205.

23 Q. Wu, J. Cen, K. R. Goodman, M. G. White, G. Ramakrishnan and A. Orlov, Understanding the interactions of $\mathrm{CO}_{2}$ with doped and undoped $\mathrm{SrTiO}_{3}$, ChemSusChem, 2016, 9, 1889-1897.

24 H.-C. Chen, C.-W. Huang, J. C. Wu and S.-T. Lin, Theoretical investigation of the metal-doped $\mathrm{SrTiO}_{3}$ photocatalysts for water splitting, J. Phys. Chem. C, 2012, 116, 7897-7903.

25 J. Baniecki, M. Ishii, K. Kurihara, K. Yamanaka, T. Yano, K. Shinozaki, T. Imada, K. Nozaki and N. Kin, Photoemission and quantum chemical study of $\mathrm{SrTiO}_{3}$ (001) surfaces and their interaction with $\mathrm{CO}_{2}$, Phys. Rev. B: Condens. Matter Mater. Phys., 2008, 78, 195415.

26 J. Baniecki, M. Ishii, K. Kurihara, K. Yamanaka, T. Yano, K. Shinozaki, T. Imada and Y. Kobayashi, Chemisorption of water and carbon dioxide on nanostructured $\mathrm{BaTiO}_{3}-$ $\mathrm{SrTiO}_{3}$ (001) surfaces, J. Appl. Phys., 2009, 106, 054109.

27 B. Modak and S. K. Ghosh, Origin of enhanced visible light driven water splitting by (Rh, Sb)-SrTiO 3 , Phys. Chem. Chem. Phys., 2015, 17, 15274-15283.

28 S. Woo, H. Jeong, S. A. Lee, H. Seo, M. Lacotte, A. David, H. Y. Kim, W. Prellier, Y. Kim and W. S. Choi, Surface properties of atomically at poly-crystalline $\mathrm{SrTiO}_{3}, \mathrm{Sci}$. Rep., 2015, 5, 8822.

29 D. Halwidl, B. Stöger, W. Mayr-Schmölzer, J. Pavelec, D. Fobes, J. Peng, Z. Mao, G. S. Parkinson, M. Schmid, F. Mittendorfer, et al., Adsorption of water at the SrO surface of ruthenates, Nat. Mater., 2016, 15, 450.

30 M. Burriel, S. Wilkins, J. P. Hill, M. A. Muñoz-Márquez, H. H. Brongersma, J. A. Kilner, M. P. Ryan and S. J. Skinner, Absence of $\mathrm{Ni}$ on the outer surface of $\mathrm{Sr}$ doped $\mathrm{La}_{2} \mathrm{NiO}_{4}$ single crystals, Energy Environ. Sci., 2014, 7, 311-316.

31 K. Momma and F. Izumi, VESTA3 for three-dimensional visualization of crystal, volumetric and morphology data, $J$. Appl. Crystallogr., 2011, 44, 1272-1276.

32 K. Reuter and M. Scheffer, Composition, structure, and stability of $\mathrm{RuO}_{2}$ (110) as a function of oxygen pressure, Phys. Rev. B: Condens. Matter Mater. Phys., 2001, 65, 35406.

33 U. Terranova and D. Bowler, Effect of hydration of the $\mathrm{TiO}_{2}$ anatase (101) substrate on the atomic layer deposition of alumina films, J. Mater. Chem., 2011, 21, 4197-4203.

34 https://janaf.nist.gov/janaf4pdf.html.
35 G. Kresse and J. Hafner, Ab initio molecular dynamics for liquid metals, Phys. Rev. B: Condens. Matter Mater. Phys., 1993, 47, 558-561.

36 G. Kresse and J. Furthmüller, Efficiency of ab-initio total energy calculations for metals and semiconductors using a plane-wave basis set, Comput. Mater. Sci., 1996, 6, 15-50.

37 J. P. Perdew, K. Burke and M. Ernzerhof, Generalized gradient approximation made simple, Phys. Rev. Lett., 1996, 77, 3865.

38 P. E. Blöchl, Projector augmented-wave method, Phys. Rev. B: Condens. Matter Mater. Phys., 1994, 50, 17953.

39 H. J. Monkhorst and J. D. Pack, Special points for Brillouinzone integrations, Phys. Rev. B: Solid State, 1976, 13, 5188.

40 G. Henkelman, B. P. Uberuaga and H. Jónsson, A climbing image nudged elastic band method for finding saddle points and minimum energy paths, J. Chem. Phys., 2000, 113, 9901-9904.

41 C. Kunkel, F. Viñes and F. Illas, Transition metal carbides as novel materials for $\mathrm{CO}_{2}$ capture, storage, and activation, Energy Environ. Sci., 2016, 9, 141-144.

42 K. V. Sopiha, O. I. Malyi, C. Persson and P. Wu, Band gap modulation of $\mathrm{SrTiO}_{3}$ upon $\mathrm{CO}_{2}$ adsorption, Phys. Chem. Chem. Phys., 2017, 19, 16629-16637.

$43 \mathrm{H}$. Guhl, W. Miller and K. Reuter, Water adsorption and dissociation on $\mathrm{SrTiO}_{3}$ (001) revisited: A density functional theory study, Phys. Rev. B: Condens. Matter Mater. Phys., 2010, 81, 155455.

44 W.-J. Yin, B. Wen, S. Bandaru, M. Krack, M. Lau and L.-M. Liu, The effect of excess electron and hole on $\mathrm{CO}_{2}$ adsorption and activation on rutile (110) surface, Sci. Rep., 2016, 6, 23298.

45 K. C. Ko, S. T. Bromley, J. Y. Lee and F. Illas, Size-dependent level alignment between rutile and anatase $\mathrm{TiO}_{2}$ nanoparticles: implications for photocatalysis, J. Phys. Chem. Lett., 2017, 8, 5593-5598.

46 B. S. Kwak and M. Kang, Photocatalytic reduction of $\mathrm{CO}_{2}$ with $\mathrm{H}_{2} \mathrm{O}$ using perovskite $\mathrm{Ca}_{\mathrm{x}} \mathrm{Ti}_{\mathrm{y}} \mathrm{O}_{3}$, Appl. Surf. Sci., 2015, 337, 138-144.

47 S. Carlotto, M. M. Natile, A. Glisenti and A. Vittadini, Adsorption of small molecules at the cobalt-doped $\mathrm{SrTiO}_{3}$ (001) surface: A first-principles investigation, Surf. Sci., 2015, 633, 68-76.

48 R. D. Shannon, Revised effective ionic radii and systematic studies of interatomic distances in halides and chalcogenides, Acta Crystallogr., Sect. A: Cryst. Phys., Diffr., Theor. Gen. Crystallogr., 1976, 32, 751-767. 